\title{
Use of Sourdough in Low FODMAP Baking
}

\author{
Jussi Loponen ${ }^{1}$ (D) and Michael G. Gänzle ${ }^{2, *(1)}$ \\ 1 Fazer Group, 01230 Vantaa, Finland; jussi.loponen@fazer.com \\ 2 Department of Agricultural, Food and Nutritional Science, University of Alberta, \\ Edmonton, AB T6G 2P5, Canada \\ * Correspondence: mgaenzle@ualberta.ca; Tel.: +1-780-492-0774
}

Received: 3 June 2018; Accepted: 19 June 2018; Published: 22 June 2018

\begin{abstract}
A low FODMAP (fermentable oligosaccharides, disaccharides, monosaccharides, and polyols) diet allows most irritable bowel syndrome (IBS) patients to manage their gastrointestinal symptoms by avoiding FODMAP-containing foods, such as onions, pulses, and products made from wheat or rye. The downside of a low FODMAP diet is the reduced intake of dietary fiber. Applying sourdoughs - with specific FODMAP-targeting metabolic properties-to wholegrain bread making can help to remarkably reduce the content of FODMAPs in bread without affecting the content of the slowly fermented and well-tolerated dietary fiber. In this review, we outline the metabolism of FODMAPs in conventional sourdoughs and outline concepts related to fructan and mannitol metabolism that allow development of low FODMAP sourdough bread. We also summarize clinical studies where low FODMAP but high fiber, rye sourdough bread was tested for its effects on gut fermentation and gastrointestinal symptoms with very promising results. The sourdough bread-making process offers a means to develop natural and fiber-rich low FODMAP bakery products for IBS patients and thereby help them to increase their dietary fiber intake.
\end{abstract}

Keywords: sourdough; FODMAP; fructan; mannitol; lactobacilli; irritable bowel syndrome (IBS); non-celiac wheat intolerance

\section{Introduction}

Fermentable oligosaccharides, disaccharides, monosaccharides, and polyols (FODMAPs) have beneficial and adverse health effects [1]. Oligosaccharides that are not hydrolyzed and absorbed in the small intestine are rapidly fermented by intestinal microbiota in the terminal ileum and the proximal colon [2,3]. Diverse FODMAPs that are fermented by intestinal microbiota consistently cause adverse symptoms when a dose of about $0.3 \mathrm{~g} / \mathrm{kg}$ body weight, corresponding to about $15 \mathrm{~g} /$ day, is exceeded [4,5]. Adverse symptoms include osmotic diarrhea, intestinal distension, and bloating $[5,6]$. The extent of the adverse symptoms decreases with the degree of polymerization because of the reduced osmotic load of oligosaccharides in the small intestine, and the reduced rate of fermentation [6]. Adverse effects are not described for non-digestible polysaccharides, which are fermented at a much lower rate [7]. Microbiota in the terminal ileum include proteobacteria and lactic acid bacteria as the dominant representatives; ileal microbiota effectively ferment mono- and disaccharides but typically lack extracellular enzymes for hydrolysis of higher oligosaccharides and polysaccharides [6]. The sensitivity of individuals to adverse symptoms caused by FODMAPs is highly variable; adverse symptoms are often linked to irritable bowel syndrome (IBS). The sensitivity to gas pressure and pain varies highly among individuals; moreover, intestinal microbiota adapt toward the fermentation of specific oligosaccharides; this adaptation reduces or eliminates adverse symptoms [8]. Many FODMAPs are conditionally digestible depending on the genetic status of the host. About $35 \%$ of humans are lactase-persistent and digest lactose while lactose is a non-digestible 
FODMAP in the remainder of the population [9]. A substantial proportion of humans are fructose intolerant; the proportion of fructose intolerant individuals among patients with IBS was reported to be over $60 \%[10,11]$. Fructose absorption is highly dependent on the presence of equimolar amounts of glucose as uptake from the small intestine uses the same transport channels [10]. A rare variation in the sucrose-isomaltase gene reduces the digestibility of sucrose, including sucrose in the FODMAPs; this genetic variant also predisposes for IBS [12].

Health beneficial or prebiotic effects of oligosaccharides relate to the bacterial conversion of oligosaccharides to short chain fatty acids $[1,13]$. These short chain fatty acids increase the energy harvest from carbohydrates that escape small intestinal hydrolysis and absorption, improve intestinal barrier properties and resistance to enteric infections, and exert systemic effects related to inflammation, cognitive functions, and behavior through specific recognition with G-protein coupled receptors (for reviews, see $[1,7,13])$. Of note, oligomeric fructans, for which health beneficial prebiotic effects were most consistently demonstrated [13], appear also of particular concern for adverse effects in IBS [6]. Adverse and beneficial effects of FODMAPs are thus interconnected and partially related to the same mechanisms, bacterial fermentation. Consequently, a reduction of adverse symptoms in IBS by a low FODMAP diet also increased the luminal $\mathrm{pH}$ and reduced the abundance of bifidobacteria and butyrate-producing colonic bacteria $[14,15]$. While the term FODMAPs indiscriminately includes all oligosaccharides, different compounds were reported to have divergent effects. Supplementation of a low FODMAP diet with $\beta$-galacto-oligosaccharides was reported to improve IBS symptoms relative to a low FODMAP diet [16]. In other words, replacement of FODMAPs with different categories of FODMAPs may improve symptoms of IBS without the adverse consequences of a low fiber diet [1].

Wheat and rye are major contributors to the dietary intake of low molecular weight fructans [17] but whole grain products also are major contributors to the intake of dietary fiber [7]. Fermentation processes during baking may allow conversion or degradation of FODMAPs without reducing the overall dietary fiber content of bread [18]. This review aims to summarize current knowledge on the use of conventional and sourdough baking in the production of low FODMAP bread.

\section{FODMAPs as Contributors to Non-Celiac Wheat Sensitivity?}

Non-celiac wheat sensitivity refers to syndromes where components of wheat cause intestinal symptoms. Triggers and mechanisms of the syndrome are poorly described; non-celiac wheat sensitivity is often self-diagnosed or assessed after exclusion of celiac disease and wheat allergy $[19,20]$. Non-celiac wheat sensitivity overlaps significantly with IBS [20]. Non-celiac wheat sensitivity has also been described as non-gluten wheat sensitivity since gluten apparently is not a major trigger in these symptoms [21]. While a contribution of FODMAPs to symptoms in IBS is increasingly supported by clinical trials, their role in non-celiac wheat sensitivity is not as well documented. FODMAPs and amylase trypsin inhibitors (ATIs) were suggested as likely non-gluten triggers of these symptoms $[19,20]$. It is likely that Triticeae cereals other than wheat, such as rye and barley, are also potential triggers of wheat sensitivity because they also contain fructans and ATIs.

\section{FODMAPs in Cereals and FODMAP Metabolism in Conventional Sourdoughs}

Resting grains of wheat and rye contain only low levels of monosaccharides; the major oligosaccharides are sucrose, raffinose, and fructans (Table 1). During sourdough fermentation, amylase and glucoamylase activities of wheat and rye flour release maltose and glucose, respectively, from damaged starch [18]. The fructans of cereal grains are graminan-type fructans, which are oligosaccharides built of mixed-linkage fructose units [22]. Fructans in wheat and rye are concentrated in the outer layers of the grain and have an average degree of polymerization (DP) of 5-6; 1-kestose and nystose account for only a minor proportion of the overall fructans (Table 1) [23]. Additional non-starch polysaccharides include arabinoxylans and $\beta$-glucans as the major components, polysaccharides composed of mannose, galactose, and galacturonic acid, and trace amounts of pectin (Table 1). In addition to polysaccharides and FODMAPs that are present in the grain, polysaccharides, 
oligosaccharides, and polyols can be produced by bacterial activity during sourdough fermentation. An overview of the conversion and production of FODMAPs in sourdough fermentation is provided in Figure 1.

During bread making, the fructans undergo partial degradation due to invertase activity present in yeast. The remaining fructan has a lower DP than the native fructan of flour. Low molecular weight fructans may be under-estimated when analyzing fructan in dough; in addition, they are fermented more rapidly than fructans with a higher molecular weight. The fate of fructans is valid for sourdough fermentation, i.e., grain fructans degrade to some extent but in the case of sourdough, the released fructose is also partially converted to mannitol by sourdough lactobacilli. Mannitol is a polyol that is rapidly fermented by gut microbiota. Thus, for accurate FODMAP quantification, mannitol levels in sourdough breads should also be determined. In the following sections, we outline the carbohydrate metabolism in sourdoughs. This is relevant to understand when the focus is in changes of FODMAPs in sourdough bread making.

Table 1. Content of oligosaccharides and non-starch polysaccharides (\%) in wheat and rye grains.

\begin{tabular}{ccc}
\hline Saccharide & Wheat & Rye \\
\hline Arabinoxylans & $6-7$ & $7-12$ \\
3-Glucans including lignified cellulose & $0.3-3$ & $2-3$ \\
Pectin & trace & trace \\
Mannans, galactans, and galacturonans & $1-1.5$ & n.d. \\
Fructans & $1-2$ & $4.3-5$ \\
1-Kestose & 0.1 & 0.3 \\
Nystose & 0.03 & 0.1 \\
Sucrose & $0.6-1.0$ & $1.2-1.8$ \\
Maltose & trace & trace \\
Raffinose & $0.2-0.7$ & $0.1-0.7$ \\
Stachyose & trace & trace \\
\hline
\end{tabular}

Compiled with information from [17,23-31]; n.d., not determined.

In straight dough processes, the dough is fermented with baker's yeast as the sole fermentation organism; the addition of high cell counts of $S$. cerevisiae, 1-2\% biomass corresponding to about $10^{8} \mathrm{cfu} / \mathrm{g}$, achieves leavening after a fermentation time of $2 \mathrm{~h}$ or less. In sourdough baking, lactic acid bacteria are used as the second group of organisms; moreover, part of the flour is fermented for an extended period of time. The inclusion of lactic acid bacteria extends the metabolic capacity of the fermentation microbiota; the extended fermentation time strongly enhances the contribution of flour enzymes to the conversion and degradation of dough components [18]. Type I sourdoughs are typically fermented between 15 and $30^{\circ} \mathrm{C}$ and they have traditionally been used as the sole leavening agent in bread making. To ensure a sufficient metabolic activity and leavening capacity, type I sourdoughs are propagated through one to three fermentation steps prior to mixing the bread dough $[27,32]$. Fermentation procedures that use sourdough as the sole leavening agent typically result in $\sim 10 \%$ of the flour being fermented for $>12 \mathrm{~h}, 20-30 \%$ fermented for $>6 \mathrm{~h}$, and all of the flour fermented for $2-3 \mathrm{~h}$, i.e., the time required for dough rest and proofing [33,34]. Fermentation organisms in type I sourdoughs generally include Lactobacillus sanfranciscensis and Kazachstania humilis (syn. Candida milleri) and S. cerevisiae or S. exiguus. Lactobacilli of the L. brevis, L. plantarum, and L. reuteri groups are also represented in type I sourdoughs [32,35]. Industrial bread production generally includes baker's yeast as the leavening agent; sourdough fermentations in industrial baking (type I or II sourdoughs) aim at dough acidification to improve the baking quality of rye flour, at supporting the leavening capacity of baker's yeast, and as baking improver [32-34]. Fermentation conditions depend on the technological aim of the fermentation and are often specific for a specific production site; typically, $5-20 \%$ of the flour is fermented for $>12 \mathrm{~h}$ while the remainder of the flour is fermented for $\sim 2 \mathrm{~h}$, corresponding to dough rest, shaping, and proofing [33,34]. Type II sourdough fermentation takes 
place at around $40{ }^{\circ} \mathrm{C}$ and the microbiota typically comprise organisms of the L. delbrueckii group (e.g., L. amylovorans and L. johnsonii) and organisms of the L. reuteri group (e.g., L. reuteri, L. pontis, and L. panis) $[32,36]$. Sourdough microbiota are metabolically active if the sourdough is fermented at the bakery but inactivated if the sourdough is stabilized by drying or pasteurization prior to use in baking [34].

Sucrose is metabolized rapidly by invertase activity of S. cerevisiae. Yeast invertase is an extracellular or cell wall-bound enzyme and is secreted in excess of the yeast's capacity to ferment the hydrolysis products [37]. Sucrose metabolism in lactic acid bacteria is mediated by sucrose phosphorylase or sucrose-1-phosphate hydrolase [38]. Sucrose metabolism and the metabolism of other oligosaccharides in homofermentative lactic acid bacteria is repressed by glucose [39]; in contrast, sucrose conversion in heterofermentative lactic acid bacteria is induced by the substrate but not repressed by glucose $[40,41]$. Fructose is utilized as a carbon source by homofermentative lactic acid bacteria but used as an electron acceptor for the regeneration of reduced cofactors by most heterofermentative lactobacilli [41,42]. Sourdough lactic acid bacteria also harbor extracellular glucansucrases or fructansucrases, which convert sucrose to indigestible poly- and oligosaccharides. These enzymes are frequently present in Leuconostoc spp., Weissella spp., and species of the L. reuteri and L. delbrueckii groups but are also present in other lactobacilli including L. sanfranciscensis [43,44]. Glucansucrases convert sucrose to polymeric glucans, isomalto-oligosaccharides, and fructose; fructansucrases catalyze the conversion to levan or inulin, fructo-oligosaccharides, and glucose [44]. Sucrose conversion by glucansucrases and fructansucrases accumulated isomalto-oligosaccharides and fructo-oligosaccharides, respectively, in wheat and sorghum sourdoughs; however, accumulation of oligosaccharides to relevant concentrations is observed only when sucrose is added to the sourdough [45,46]. Glucansucrases and the hydrolase activity of fructansucrases generally also release fructose, which is converted to the polyol mannitol by heterofermentative lactic acid bacteria [41,43]. In traditional sourdough fermentations, mannitol accumulates to $10-20 \mathrm{mmol} / \mathrm{kg}$ in wheat and $50 \mathrm{mmol} / \mathrm{kg}$ in rye, corresponding to $0.2-0.4 \%$ and $0.9 \%$, respectively; the mannitol concentration is increased in direct proportion to the sucrose addition to sourdoughs [47]. Weissella spp. are exceptional because the majority of strains do not produce mannitol from fructose [45].

Lactic acid bacteria metabolize raffinose by sequential activity of extracellular levansucrase to convert raffinose to melibiose and fructose or fructan, followed by melibiose transport and intracellular hydrolysis by $\alpha$-galactosidase. An alternative pathway involves raffinose transport and sequential hydrolysis by intracellular $\alpha$-galactosidase to convert raffinose to sucrose and galactose and sucrose phosphorylase [48]. Metabolism by extracellular levansucrase with intracellular $\alpha$-galactosidase is faster than the alternate pathway using two intracellular enzymes, presumably because the disaccharide melibiose is transported faster than raffinose [48]. Raffinose metabolism in heterofermentative lactobacilli is not subject to carbon catabolite repression [49] and the relatively high concentrations of raffinose and raffinose level oligosaccharides in pulse flours are rapidly degraded during fermentation [48]. Type I sourdough microbiota and most strains of S. cerevisiae are raffinose negative. Nevertheless, levansucrase from L. sanfranciscensis and/or yeast invertase converts raffinose to fructose and melibiose $[43,50]$.

The content of fructans is reduced in straight dough processing to $1-1.5 \%$ fructans in wheat bread and about $3 \%$ in rye bread [51]. Fructans are not degraded in simulated sourdoughs without microbial activity but invertase activity of S. cerevisiae and Kazachstania humilis results in partial hydrolysis of flour fructans $[52,53]$. In a straight dough process, the rate of fructan hydrolysis decreases in the order trisaccharides $>$ tetrasaccharides $>$ pentasaccharides and only a small proportion of higher fructans are degraded [54]. Hydrolysis of fructans is mediated by yeast. However, dimerization of the enzyme reduces the activity towards kestose and nystose and sterically prevents access of oligosaccharides with a DP of more than four to the catalytic site [55]. Metabolism of fructans in lactobacilli is mediated by oligosaccharide transport through the ATP-Bbinding-Cassette transporter MsmEFGK or the phosphotransferase (PTS) system PTS1Bca, followed by hydrolysis through intracellular fructosidases 
or phospho-fructosidases, respectively [38]. Oligosaccharide transport by MsmEFGK and PTS1BCA is limited to fructans with a DP of four or less [56,57]. Metabolic enzymes for fructo-oligosaccharide (FOS) catabolism are frequent in homofermentative lactobacilli where FOS degradation is repressed by glucose [58] but are very infrequently found in heterofermentative lactobacilli [38,43,49]. Intracellular metabolism of FOS by lactobacilli thus does not contribute to the degradation of fructans in wheat or rye sourdoughs.

In summary, conventional dough fermentations, including sourdough fermentations, result in decreased levels of FODMAPs but may generate FODMAPs from the digestible carbohydrates sucrose and fructose (Figure 1). Low FODMAP baking thus necessitates dedicated approaches, particularly involving fructan- and mannitol-degrading organisms.

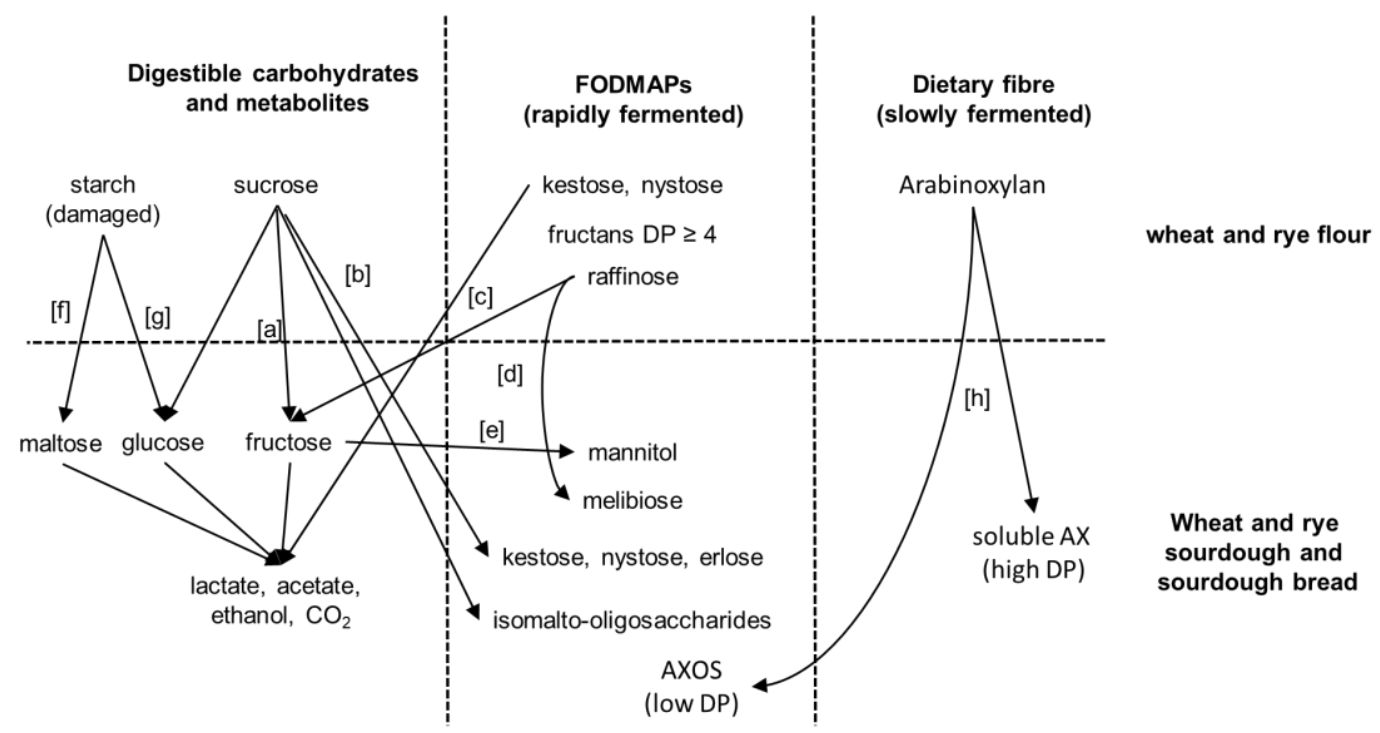

Figure 1. Conversion and generation of fermentable oligosaccharides, disaccharides, monosaccharides, and polyols (FODMAPs) in wheat and rye sourdoughs. Sucrose hydrolysis by yeast invertase or fructosidases of lactic acid bacteria [a]. Oligosaccharide formation by glucansucrases to form isomalto-oligosaccharides, or by fructansucrases to form kestose, nystose, and erlose from sucrose [b]. Kestose and nystose degradation by yeast invertase or by intracellular (phospho)-fructosidases of lactic acid bacteria [c]. Raffinose conversion by yeast invertase and levansucrase from lactic acid bacteria [d]. Fructose conversion by mannitol-dehydrogenase from heterofermentative lactic acid bacteria [e]. Starch conversion to maltose and glucose by flour amylases and gluco-amylase [f,g]. Exogenous xylanases are used in baking to increase the amount of soluble pentosane (arabinoxylan, AX) to improve bread properties, which can produce low DP arabinoxylan oligosaccharides (AXOS) along soluble high-DP arabinoxylan fragments [h].

\section{Concepts for Low FODMAP Sourdough Baking}

Degradation of fructans with a DP of more than four requires extracellular fructanases. Baker's yeast S. cerevisiae does not express extracellular fructanase. However, Kluyveromyces marxianus was suggested as an alternative leavening agent with extracellular fructanase activity [53,59]. $K$. marxianus is maltose negative and most strains do not provide sufficient $\mathrm{CO}_{2}$ production for dough leavening; the use of $K$. marxianus in low FODMAP baking thus requires co-culture with S. cerevisiae [53] or selection of K. marxianus strains with sufficient leavening power and addition of amyloglucosidase to provide glucose for K. marxianus metabolism $[53,59]$. Dough fermentation with K. marxianus alone or in co-culture with $S$. cerevisiae allowed production of experimental breads with a low fructan content and a volume and sensory properties matching those of experimental breads produced with baker's yeast [53,59]. 
Extracellular glycosyl hydrolases are exceptional in lactobacilli [38]; accordingly, only a few strains with extracellular fructanase activity have been characterized (Figure 2). The extracellular GH32 $\beta$-fructanase FosE was characterized in L. paracasei [60]. FosE is an extracellular enzyme that is induced by fructose, sucrose, or inulin but repressed by glucose [60]. BLAST analysis frequently identified homologues of this enzyme in other strains of the L. casei group and in few strains of the L. salivarius group (Figure 2 and data not shown). The $\beta$-fructanase FruA of Streptococcus mutans is extracellular with an LPXTG cell wall anchor; the enzyme has less than $40 \%$ amino acid identity to FosE ([61] Figure 2). FruA of $S$. mutans plays a critical role in fructan degradation and the virulence of oral streptococci; BLAST analysis frequently identified homologues of FruA in other streptococci (Figure 2). Only five of the more than 1500 genome sequences assigned to the genus Lactobacillus harbors FruA homologues; this low frequency suggests that this $\beta$-fructanase is not necessary for the lifestyle of lactobacilli but only infrequently acquired by lateral gene transfer. Two of the species with FruA activity, L. amylovorus and L. crispatus, match species that are typically found in type II sourdoughs.

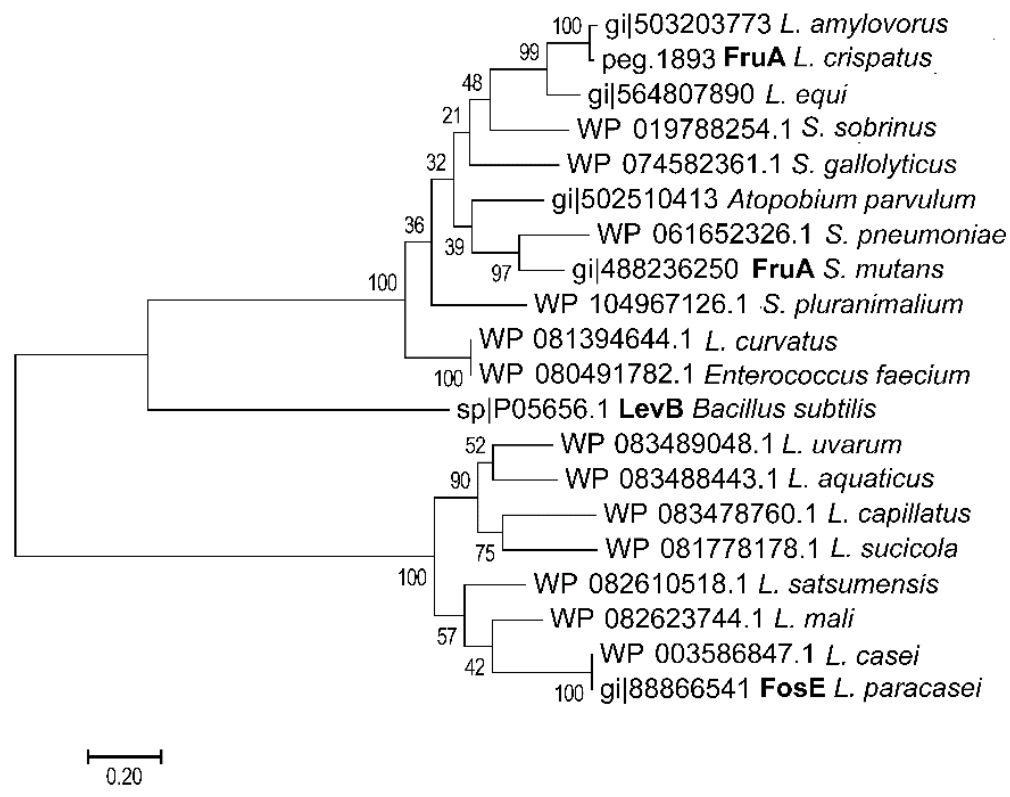

Figure 2. Molecular phylogenetic analysis of extracellular fructanases in lactic acid bacteria by the Maximum Likelihood method. The evolutionary history was inferred by using the Maximum Likelihood method; the tree is drawn to scale with branch lengths measured in the number of substitutions per site. Evolutionary analyses were conducted in MEGA7. Sequences were retrieved by NCBI Blast using the fructanase of L. crispatus [62] and the inulinase of L. paracasei [60] as query sequence. Sequences from lactic acid bacteria (Lactobacillales) with a more than $80 \%$ coverage and more than $50 \%$ amino acid identity were retrieved and aligned by ClustalW in MEGA 7.0. A levanase of Bacillus subtilis was included for comparison. Only one representative sequence for each bacterial species was chosen; sequences of 15 Streptococcus spp. which were all similar to sequences of other streptococci were omitted from the tree. The two Lactobacillus enzymes that were characterized biochemically are printed in bold.

Type I and type II sourdough microbiota generally include heterofermentative lactobacilli that convert fructose to mannitol. Degradation of mannitol in low FODMAP baking therefore requires mannitol-fermenting lactobacilli. Mannitol metabolism in lactobacilli is mediated by a mannitol-specific PTS system, followed by conversion by mannitol-1-phosphate-dehydrogenase to fructose-1-phospyate [63]. Enzymes for mannitol conversion are present in homofermentative lactobacilli of the L. delbrueckii, L. casei, L. plantarum and L. salivarius groups, likely representing trophic 
relationships with heterofermentative lactobacilli. In analogy to other PTS systems in lactobacilli, mannitol metabolism in homofermentative lactobacilli is repressed by glucose $[39,41,58]$.

Glucose and maltose levels in wheat and rye sourdoughs and consequently carbon catabolite repression in homofermentative lactobacilli and yeasts $[38,41]$ are determined by the level of damaged starch and the $\beta$-amylase and amyloglucosidase activity in flour (Figure $1 ;[18,64]$ ). If enzyme activity and the level of damaged starch in flour are low, sucrose, raffinose, and fructans become the most readily available carbohydrates [64]. The composition of the microbiota in rye sourdoughs that are low in damaged starch match the composition in other type II sourdoughs with organisms of the L. delbrueckii group including L. crispatus, L. amylovorus, and L. ultuensis, and organisms of the $L$. reuteri group including $L$. frumentii and $L$. pontis as the dominant members $[32,35,65]$. The restricted availability of maltose and glucose, however, selects for strains expressing an exceptional fructanase (Figure 2, [62,65]). The prevailing enzyme activity is an extracellular exofructanase (Figure 2), which exhibits more than $80 \%$ of the maximum activity in the $\mathrm{pH}$ range of 4-6 and the temperature range of $30-60{ }^{\circ} \mathrm{C}$ [62]. Fructan hydrolysis in sourdough releases fructose that is partially converted to mannitol by L. reuteri group organisms (Figure 3). However, the restriction of carbohydrate sources also allows for mannitol conversion after fructans are completely consumed (Figure 3) and results in a virtually zero FODMAP sourdough. The use of this zero FODMAP sourdough in low FODMAP rye bread making involves the addition of unfermented rye flour, which is fermented for only a short time [65]. Nevertheless, the choice of appropriate raw materials and the use of FruA-positive and mannitol-fermenting lactobacilli allows fructan degradation in rye and rye sourdoughs for the production of bread with a low content of fructans and mannitol but a comparable fiber content when compared to regular bread [66-68].

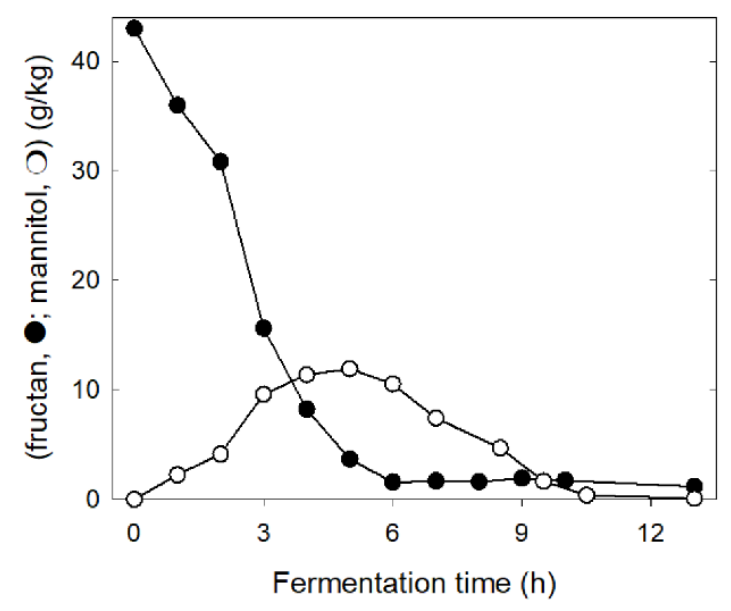

Figure 3. Degradation of fructans (black) and the formation and degradation of mannitol (white) in a type II rye sourdough. Sourdough microbiota consist of fructan-degrading strains of the L. delbrueckii group and heterofermentative strains of the L. reuteri group, which convert fructose to mannitol. Drawn with data from [65].

\section{Proof of Concept from Clinical Trials with Low FODMAP Rye Bread}

Two clinical trials done with IBS patients verified that low FODMAP rye bread made by using the above described zero FODMAP sourdough influences the gastrointestinal symptoms and the extent of gas production generated in intestinal fermentation. In the first study in a randomized double-blind controlled crossover study, it was shown that low FODMAP rye bread caused less flatulence, less abdominal pain, fewer cramps, and less stomach rumbling than regular rye bread [66]. Of note, the low FODMAP bread retained a high dietary fiber content $(10 \mathrm{~g} / 100 \mathrm{~g})$ although the FODMAP levels were lowered to one third [66]. Including the low FODMAP rye bread thus also increased the dietary fiber intake to the recommended level in IBS patients, avoiding drawbacks 
of the other low FODMAP diets [15]. A second randomized double-blind controlled crossover study evaluated the amount of breath hydrogen levels after consuming low FODMAP rye bread or regular rye bread [68]. Low FODMAP rye bread reduced the generation of hydrogen by colonic fermentation [68]. This study showed that significant differences between bread types may occur in their postprandial effects.

\section{Conclusions and Future Directions}

Conventional sourdough baking reduces and converts FODMAPs in rye and wheat flour; however, the extent of FODMAP reduction is dependent on the fermentation organisms, the fermentation process, the grain raw material, and the sourdough dosage to the final bread dough. The production of low FODMAP bread requires extracellular fructanase activity; sourdough fermentation with lactobacilli expressing fructanases or the use of fructanase-positive yeasts provide wheat or rye breads with a low FODMAP content. Low FODMAP bread can help to restrict the intake of FODMAPs but at the same time increase the intake of slowly fermentable dietary fiber in IBS patients. High fiber/low FODMAP bread likely prevents the depletion of intestinal bifidobacteria that has been observed on other low FODMAP diets $[14,15]$ and shows promise in reducing symptoms of IBS.

Anecdotal evidence links sourdough bread to improved tolerance of wheat in individuals with non-celiac wheat sensitivities [69]. In addition to the degradation of FODMAPs during sourdough fermentation, reduction and degradation of wheat amylase trypsin inhibitors may improve wheat tolerance in some individuals [67]. Amylase trypsin inhibitors are suggested to play a role in intestinal and extra-intestinal symptoms as they induce inflammatory reactions [70]. Amylase trypsin inhibitors are highly disulfide-bonded proteins; reduction of disulfide bonds reduces bioactivity and accelerates proteolytic digestion. Sourdough fermentation generates reducing conditions and supports reduction and hydrolysis of highly disulfide-bonded proteins that resist digestion in unfermented dough [71]. A pilot trial recruiting IBS patients with non-celiac wheat sensitivity, however, showed no improvement of intestinal symptoms after consuming sourdough wheat bread compared with industrial wheat bread [67]. Difficulties in identifying the protective effects of sourdough fermentation in non-celiac wheat intolerance relate to the poorly identified and likely multifactorial triggers of (self-diagnosed) non-celiac wheat sensitivity, and the inherent difficulties in blinding consumption of wheat or wheat sourdough products in clinical trials [67]. Despite the lack of support from clinical trials, sourdough-derived solutions likely play a significant role when developing healthier bakery products for people with non-gluten wheat sensitivities.

Author Contributions: Conceptualization, writing and editing: M.G.G. and J.L.

Funding: M.G.G. is supported by the Canada Research Chairs Program; J.L. is employed by a Fazer Group company Oy Karl Fazer Ab.

Conflicts of Interest: The authors declare no conflict of interest. The funding sponsors had no role in the writing of the manuscript, and in the decision to publish the review article.

\section{References}

1. Yan, Y.L.; Hu, Y.; Gänzle, M.G. Prebiotics, FODMAPs and dietary fibre-conflicting concepts in development of functional food products? Curr. Opin. Food Sci. 2018, 20, 30-37. [CrossRef]

2. Booijink, C.C.; El-Aidy, S.; Rajilić-Stojanović, M.; Heilig, H.G.; Troost, F.J.; Smidt, H.; Kleerebezem, M.; De Vos, W.M.; Zoetendal, E.G. High temporal and inter-individual variation detected in the human ileal microbiota. Environ. Microbiol. 2010, 12, 3213-3227. [CrossRef] [PubMed]

3. Zoetendal, E.G.; Raes, J.; van den Bogert, B.; Arumugam, M.; Booijink, C.C.; Troost, F.J; Bork, P.; Wels, M.; de Vos, W.M.; Kleerebezem, M. The human small intestinal microbiota is driven by rapid uptake and conversion of simple carbohydrates. ISME J. 2012, 6, 1415-1426. [CrossRef] [PubMed]

4. Oku, T.; Nakamura, S. Digestion, absorption, fermentation, and metabolism of functional sugar substitutes and their available energy. Pure Appl. Chem. 2002, 7, 1253-1261. [CrossRef] 
5. Oku, T.; Nakamura, S. Threshold for transitory diarrhea induced by ingestion of xylitol and lactitol in young male and female adults. J. Nutr. Sci. Vitaminol. (Tokyo) 2007, 53, 13-20. [CrossRef] [PubMed]

6. Murray, K.; Wilkinson-Smith, V.; Hoad, C.; Costigan, C.; Cox, E.; Lam, C.; Marciani, L.; Gowland, P.; Spiller, R.C. Differential effects of FODMAPs (fermentable oligo-, di-, mono-saccharides and polyols) on small and large intestinal contents in healthy subjects shown by MRI. Am. J. Gastroenterol. 2014, 109, 110-119. [CrossRef] [PubMed]

7. Hamaker, B.R.; Tuncil, Y.E. A perspective on the complexity of dietary fiber structures and their potential effect on the gut microbiota. J. Mol. Biol. 2014, 426, 3838-3850. [CrossRef] [PubMed]

8. Azcarate-Peril, M.A.; Ritter, A.J.; Savaiano, D.; Monteagudo-Mera, A.; Anderson, C.; Magness, S.T.; Klaenhammer, T.R. Impact of short-chain galactooligosaccharides on the gut microbiome of lactose-intolerant individuals. Proc. Natl. Acad. Sci. USA 2017, 114, E367-E375. [CrossRef] [PubMed]

9. Gerbault, P.; Liebert, A.; Itan, Y.; Powell, A.; Currat, M.; Burger, J.; Swallow, D.M.; Thomas, M.G. Evolution of lactase persistence: An example of human niche construction. Philos. Trans. R. Soc. Lond. B Biol. Sci. 2011, 366, 863-877. [CrossRef] [PubMed]

10. Latulippe, M.E.; Skoog, S.M. Fructose malabsorption and intolerance: Effects of fructose with and without simultaneous glucose ingestion. Crit. Rev. Food Sci. Nutr. 2011, 51, 583-592. [CrossRef] [PubMed]

11. Wilder-Smith, C.H.; Materna, A.; Wermelinger, C.; Schuler, J. Fructose and lactose intolerance and malabsorption testing: The relationship with symptoms in functional gastrointestinal disorders. Aliment. Pharmacol. Ther. 2013, 37, 1074-1183. [CrossRef] [PubMed]

12. Henström, M.; Diekmann, L.; Bonfiglio, F.; Hadizadeh, F.; Kuech, E.M.; von Köckritz-Blickwede, M.; Thingholm, L.B.; Zheng, T.; Assadi, G.; Dierks, C.; et al. Functional variants in the sucrase-isomaltase gene associate with increased risk of irritable bowel syndrome. Gut 2018, 67, 263-270. [CrossRef] [PubMed]

13. Bindels, L.B.; Delzenne, N.M.; Cani, P.D.; Walter, J. Towards a more comprehensive concept for prebiotics. Nat. Rev. Gastroenterol. Hepatol. 2015, 12, 303-310. [CrossRef] [PubMed]

14. Halmos, E.P.; Christophersen, C.T.; Bird, A.R.; Shepherd, S.J.; Gibson, P.R.; Muir, J.G. Diets that differ in their FODMAP content alter the colonic luminal microenvironment. Gut 2015, 64, 93-100. [CrossRef] [PubMed]

15. Staudacher, H.M.; Lomer, M.C.; Anderson, J.L.; Barrett, J.S.; Muir, J.G.; Irving, P.M.; Whelan, K. Fermentable carbohydrate restriction reduces luminal bifidobacteria and gastrointestinal symptoms in patients with irritable bowel syndrome. J. Nutr. 2012, 142, 1510-1518. [CrossRef] [PubMed]

16. Wilson, B.; Rossi, M.; Parkes, G.; Aziz, Q.; Anderson, W.; Irving, P.; Lomer, M.; Whelan, K. Prebiotic B-galacto-oligosaccharide supplementation of the low FODMAP diet improves symptoms of irritable bowel syndrome but does not prevent diet induced decline in bifidobacteria: A randomised controlled trial. Proceed. Nutr. Soc. 2017, 76. [CrossRef]

17. Campbell, J.M.; Bauer, L.L.; Fahey, G.C.; Hogarth, A.J.C.L.; Wolf, B.W.; Hunter, D.W. Selected fructooligosaccharide (1-kestose, nystose, and $1 \mathrm{~F}-\beta$-fructofuranosylnystose) composition of foods and feeds. J. Agric. Food Chem. 1997, 45, 3076-3082. [CrossRef]

18. Gänzle, M.G. Enzymatic and bacterial conversions during sourdough fermentation. Food Microbiol. 2014, 37, 2-10. [CrossRef] [PubMed]

19. De Giorgio, R.; Volta, U.; Gibson, P.R. Sensitivity to wheat, gluten and FODMAPs in IBS: Facts or fiction? Gut 2016, 65, 169-178. [CrossRef] [PubMed]

20. Schuppan, D.; Pickert, G.; Ashfaq-Khan, M.; Zevallos, V. Non-celiac wheat sensitivity: Differential diagnosis, triggers and implications. Best Pract. Res. Clin. Gastroenterol. 2015, 29, 469-476. [CrossRef] [PubMed]

21. Biesiekierski, J.R.; Peters, S.L.; Newnham, E.D.; Rosella, O.; Muir, J.G.; Gibson, P.R. No effects of gluten in patients with self-reported non-celiac gluten sensitivity after dietary reduction of fermentable, poorly absorbed, short-chain carbohydrates. Gastroenterology 2013, 145, 320-328. [CrossRef] [PubMed]

22. Verspreet, J.; Dorneza, E.; Van den Ende, W.; Delcour, C.; Courtin, C.M. Cereal grain fructans: Structure, variability and potential health effects. Trends Food Sci. Technol. 2015, 43, 32-42. [CrossRef]

23. Verspreet, J.; Pollet, A.; Cuyvers, S.; Vergauwen, R.; Van den Ende, W.; Delcour, J.A.; Courtin, C.M. A simple and accurate method for determining wheat grain fructan content and average degree of polymerization. J. Agric. Food Chem. 2012, 60, 2102-2107. [CrossRef] [PubMed]

24. Kuo, T.M.; Van Middlesworth, J.F.; Wolf, W.J. Content of raffinose oligosaccharides and sucrose in various plant seeds. J. Agric. Food Chem. 1988, 36, 32-36. [CrossRef] 
25. Vinkx, C.J.A.; Delcour, J.A. Rye (Secale cereale L.) arabinoxylans: A critical review. J. Cereal Sci. 1996, 24, 1-14. [CrossRef]

26. Grausgruber, H.; Scheiblauer, J.; Schönlechner, R.; Ruckenbauer, P.; Berghofer, E. Variability in chemical composition and biologically active constituents of cereals. In Genetic Variation for Plant Breeding; Vollmann, J., Grausgruber, H., Ruckenbauer, P., Eds.; EUCARPIA \& BOKU: Wien, Austria, 2004; pp. $23-26$. ISBN 3-900962-56-1.

27. Brandt, M.J. Bedeutung von Rohwarenkomponenten. In Handbuch Sauerteig; Brandt, M.J., Gänzle, M.G., Eds.; Behr's Verlag: Hamburg, Germany, 2005; pp. 41-56. ISBN 3-89947-166-0.

28. Haskå, L.; Nymana, M.; Andersson, R. Distribution and characterisation of fructan in wheat milling fractions. J. Cereal Sci. 2008, 48, 768-774. [CrossRef]

29. Andersson, A.A.; Andersson, R.; Piironen, V.; Lampi, A.M.; Nyström, L.; Boros, D.; Fraś, A.; Gebruers, K.; Courtin, C.M.; Delcour, J.A.; et al. Contents of dietary fibre components and their relation to associated bioactive components in whole grain wheat samples from the HEALTHGRAIN diversity screen. Food Chem. 2013, 136, 1243-1248. [CrossRef] [PubMed]

30. Chateigner-Boutin, A.L.; Bouchet, B.; Alvarado, C.; Bakan, B.; Guillon, F. The wheat grain contains pectic domains exhibiting specific spatial and development-associated distribution. PLoS ONE 2014, 9, e89620. [CrossRef] [PubMed]

31. Saulnier, L.; Guillon, F.; Chateigner-Boutin, A.-L. Cell wall deposition and metabolism in wheat grain. J. Cereal Sci. 2012, 56, 91-108. [CrossRef]

32. Gänzle, M.; Ripari, V. Composition and function of sourdough microbiota: From ecological theory to bread quality. Int. J. Food Microbiol. 2016, 239, 19-25. [CrossRef] [PubMed]

33. Brandt, M.J.; Gänzle, M.G. Handbuch Sauerteig; Behr's Verlag: Hamburg, Germany, 2005; ISBN 3-89947-166-0.

34. Brandt, M.J. Sourdough products for convenient use in baking. Food Microbiol. 2007, 24, 161-164. [CrossRef] [PubMed]

35. De Vuyst, L.; Harth, H.; Van Kerrebroeck, S.; Leroy, F. Yeast diversity of sourdoughs and associated metabolic properties and functionalities. Int. J. Food Microbiol. 2016, 239, 26-34. [CrossRef] [PubMed]

36. Gobbetti, M.; Minervini, F.; Pontonio, E.; Di Cagno, R.; De Angelis, M. Drivers for the establishment and composition of the sourdough lactic acid bacteria biota. Int. J. Food Microbiol. 2016, 239, 3-18. [CrossRef] [PubMed]

37. Perlman, D.; Halvorson, H.O. Distinct repressible mRNAs for cytoplasmic and secreted yeast invertase are encoded by a single gene. Cell 1981, 25, 525-536. [CrossRef]

38. Gänzle, M.G.; Follador, R. Metabolism of oligosaccharides and starch in lactobacilli: A review. Front. Microbiol. 2012, 3, 340. [CrossRef] [PubMed]

39. Andersson, U.; Molenaar, D.; Radström, P.; de Vos, W.M. Unity in organization and regulation of catabolic operons in Lactobacillus plantarum, Lactococcus lactis, and Listeria monocytogenes. Syst. Appl. Microbiol. 2005, 28, 187-195. [CrossRef] [PubMed]

40. Teixeira, J.S.; Abdi, R.; Su, M.S.; Schwab, C.; Gänzle, M.G. Functional characterization of sucrose phosphorylase and scrR, a regulator of sucrose metabolism in Lactobacillus reuteri. Food Microbiol. 2013, 36, 432-439. [CrossRef] [PubMed]

41. Gänzle, M.G. Lactic metabolism revisited: Metabolism of lactic acid bacteria in food fermentations and food biotechnology. Curr. Opin. Food Sci. 2015, 2, 106-117. [CrossRef]

42. Gänzle, M.G.; Vermeulen, N.; Vogel, R.F. Carbohydrate, peptide and lipid metabolism of lactic acid bacteria in sourdough. Food Microbiol. 2007, 24, 128-138. [CrossRef] [PubMed]

43. Zheng, J.; Ruan, L.; Sun, M.; Gänzle, M. A genomic view of lactobacilli and pediococci demonstrates that phylogeny matches ecology and physiology. Appl. Environ. Microbiol. 2015, 81, 7233-7243. [CrossRef] [PubMed]

44. Galle, S.; Arendt, E.K. Exopolysaccharides from sourdough lactic acid bacteria. Crit. Rev. Food Sci. Nutr. 2014, 54, 891-901. [CrossRef] [PubMed]

45. Galle, S.; Schwab, C.; Arendt, E.; Gänzle, M. Exopolysaccharide-forming Weissella strains as starter cultures for sorghum and wheat sourdoughs. J. Agric. Food Chem. 2010, 58, 5834-5841. [CrossRef] [PubMed]

46. Schwab, C.; Mastrangelo, M.; Corsetti, A.; Gänzle, M.G. Formation of oligosaccharides and polysaccharides by Lactobacillus reuteri LTH5448 and Weissella cibaria 10M in sorghum sourdoughs. Cereal Chem. 2008, 85, 679-684. [CrossRef] 
47. Korakli, M.; Rossmann, A.; Gänzle, M.G.; Vogel, R.F. Sucrose metabolism and exopolysaccharide production in wheat and rye sourdoughs by Lactobacillus sanfranciscensis. J. Agric. Food Chem. 2001, 49, 5194-5200. [CrossRef] [PubMed]

48. Teixeira, J.S.; McNeill, V.; Gänzle, M.G. Levansucrase and sucrose phoshorylase contribute to raffinose, stachyose, and verbascose metabolism by lactobacilli. Food Microbiol. 2012, 31, 278-284. [CrossRef] [PubMed]

49. Zhao, X.; Gänzle, M.G. Genetic and phenotypic analysis of carbohydrate metabolism and transport in Lactobacillus reuteri. Int. J. Food Microbiol. 2018, 272, 12-21. [CrossRef] [PubMed]

50. Ostergaard, S.; Olsson, L.; Nielsen, J. Metabolic Engineering of Saccharomyces cerevisiae. Microbiol. Mol. Biol. Rev. 2000, 64, 34-50. [CrossRef] [PubMed]

51. Whelan, K.; Abrahmsohn, O.; David, G.J.; Staudacher, H.; Irving, P.; Lomer, M.C.; Ellis, P.R. Fructan content of commonly consumed wheat, rye and gluten-free breads. Int. J. Food Sci. Nutr. 2011, 62, 498-503. [CrossRef] [PubMed]

52. Brandt, J.J.; Hammes, W.P. Einfluss von Fructosanen auf die Sauerteigfermentation. Getreide Mehl Brot 2001, 55, 341-345.

53. Struyf, N.; Laurent, J.; Verspreet, J.; Verstrepen, K.J.; Courtin, C.M. Saccharomyces cerevisiae and Kluyveromyces marxianus co-cultures allow reduction of fermentable oligo-, di-, and monosaccharides and polyols levels in whole wheat bread. J. Agric. Food Chem. 2017, 65, 8704-8713. [CrossRef] [PubMed]

54. Nilsson, U.; Öste, R.; Jägerstad, M. Cereal fructans: Hydrolysis by yeast invertase, in vitro and during fermentation. J. Cereal Sci. 1987, 6, 53-60. [CrossRef]

55. Sainz-Polo, M.A.; Ramírez-Escudero, M.; Lafraya, A.; González, B.; Marín-Navarro, J.; Polaina, J.; Sanz-Aparicio, J. Three-dimensional structure of Saccharomyces invertase: Role of a non-catalytic domain in oligomerization and substrate specificity. J. Biol. Chem. 2013, 288, 9755-9766. [CrossRef] [PubMed]

56. Kaplan, H.; Hutkins, R.W. Metabolism of fructooligosaccharides by Lactobacillus paracasei 1195. Appl. Environ. Microbiol. 2003, 69, 2217-2222. [CrossRef] [PubMed]

57. Saulnier, D.M.; Molenaar, D.; de Vos, W.M.; Gibson, G.R.; Kolida, S. Identification of prebiotic fructooligosaccharide metabolism in Lactobacillus plantarum WCFS1 through microarrays. Appl. Environ. Microbiol. 2007, 73, 1753-1765. [CrossRef] [PubMed]

58. Barrangou, R.; Azcarate-Peril, M.A.; Duong, T.; Conners, S.B.; Kelly, R.M.; Klaenhammer, T.R. Global analysis of carbohydrate utilization by Lactobacillus acidophilus using cDNA microarrays. Proc. Natl. Acad. Sci. USA 2006, 103, 3816-3821. [CrossRef] [PubMed]

59. Stuyf, N.; Vancdewiele, H.; Herrera-Malaver, B.; Verspreet, J.; Verstrepen, K.J.; Courtin, C.M. Kluyveromyces marxianus yeast enables the production of low FODMAP whole wheat breads. Food Microbiol. 2018, 76, 135-145. [CrossRef]

60. Goh, Y.J.; Lee, J.H.; Hutkins, R.W. Functional analysis of the fructooligosaccharide utilization operon in Lactobacillus paracasei 1195. Appl. Environ. Microbiol. 2007, 73, 5716-5724. [CrossRef] [PubMed]

61. Burne, R.A.; Penders, J.E. Differential localization of the Streptococcus mutans GS-5 fructan hydrolase enzyme, FruA. FEMS Microbiol. Lett. 1994, 121, 243-249. [CrossRef] [PubMed]

62. Loponen, J.; Mikola, M.; Sibakov, J. An Enzyme Exhibiting Fructan Hydrolase Activity. Patent No. WO2017220864A1, 28 December 2017.

63. Wisselink, H.W.; Moers, A.P.; Mars, A.E.; Hoefnagel, M.H.; de Vos, W.M.; Hugenholtz, J. Overproduction of heterologous mannitol 1-phosphatase: A key factor for engineering mannitol production by Lactococcus lactis. Appl. Environ. Microbiol. 2005, 71, 1507-1514. [CrossRef] [PubMed]

64. Struyf, N.; Laurent, J.; Lefevere, B.; Verspreet, J.; Verstrepen, K.J.; Courtin, C.M. Establishing the relative importance of damaged starch and fructan as sources of fermentable sugars in wheat flour and whole meal bread dough fermentations. Food Chem. 2017, 218, 89-98. [CrossRef] [PubMed]

65. Loponen, J. Low-Fructan Grain Material and a Method for Producing the Same. Patent No. WO2016113465A1, 21 July 2016.

66. Laatikainen, R.; Koskenpato, J.; Hongisto, S.M.; Loponen, J.; Poussa, T.; Hillilä, M.; Korpela, R. Randomised clinical trial: Low-FODMAP rye bread vs. regular rye bread to relieve the symptoms of irritable bowel syndrome. Aliment. Pharmacol. Ther. 2016, 44, 460-470. [CrossRef] [PubMed] 
67. Laatikainen, R.; Koskenpato, J.; Hongisto, S.M.; Loponen, J.; Poussa, T.; Huang, X.; Sontag-Strohm, T.; Salmenkari, H.; Korpela, R. Pilot study: Comparison of sourdough wheat bread and yeast-fermented wheat bread in individuals with wheat sensitivity and irritable bowel syndrome. Nutrients 2017, 9, E1215. [CrossRef] [PubMed]

68. Pirkola, L.; Laatikainen, R.; Loponen, J.; Hongisto, S.M.; Hillilä, M.; Nuora, A.; Yang, B.; Linderborg, K.M.; Freese, R. Low-FODMAP vs regular rye bread in irritable bowel syndrome: Randomized SmartPill ${ }^{\circledR}$ study. World J. Gastroenterol. 2018, 24, 1259-1268. [CrossRef] [PubMed]

69. CBC. 2013. Available online: http://www.cbc.ca/news/health/sourdough-breadmaking-cuts-glutencontent-in-baked-goods-1.2420209 (accessed on 26 May 2018).

70. Junker, Y.; Zeissig, S.; Kim, S.J.; Barisani, D.; Wieser, H.; Leffler, D.A.; Zevallos, V.; Libermann, T.A.; Dillon, S.; Freitag, T.L.; et al. Wheat amylase trypsin inhibitors drive intestinal inflammation via activation of toll-like receptor 4. J. Exp. Med. 2012, 209, 2395-2408. [CrossRef] [PubMed]

71. Loponen, J.; König, K.; Wu, J.; Gänzle, M.G. Influence of thiol metabolism of lactobacilli on egg white proteins in wheat sourdoughs. J. Agric. Food Chem. 2008, 56, 3357-3362. [CrossRef] [PubMed]

(C) 2018 by the authors. Licensee MDPI, Basel, Switzerland. This article is an open access article distributed under the terms and conditions of the Creative Commons Attribution (CC BY) license (http://creativecommons.org/licenses/by/4.0/). 